\title{
Embalagem bioativa de amido de mandioca com adição de extrato de Jamelão
}

\author{
(Syzigium cumini) \\ Edinara Lacerda Queiroz ; Sílvia Maria Almeida de Souza ${ }^{2}$ \\ 1. Bolsista PIBIC/CNPq, Graduanda em Engenharia de Alimentos, Universidade Estadual de Feira de Santana, e- \\ mail: naralacerda21@gmail.com \\ 2. Orientador, Departamento de Tecnologia, Universidade Estadual de Feira de Santana, e-mail: \\ ss_almeida@yahoo.com.br
}

PALAVRAS-CHAVE: amido de mandioca; jamelão; antioxidante.

\section{INTRODUÇÃO}

De acordo com Guilbert e Biquet (1995), atualmente, há uma grande preocupação com segurança alimentar, conveniência e preservação do meio ambiente, tais fatores impulsionado o desenvolvimento de novas embalagens e uso de novas matérias-primas para a sua elaboração. Nos últimos quarenta anos, numerosos trabalhos mostraram a utilização de filmes e envoltórios comestíveis para melhorar a conservação e qualidade de diversos alimentos frescos, transformados ou congelados.

A aplicação do amido na produção de filmes se baseia nas propriedades químicas, físicas e funcionais da amilose para formar géis e na sua capacidade para formar filmes. (SHIMAZU, MALI, GROSSMANN, 2005). Alguns dos compostos naturais comumente incorporados a estes revestimentos são os extratos de frutas.

Syzygium cumini é uma árvore nativa da índia, da família das mirtáceas, introduzida também em países tropicais. Os frutos têm coloração roxa escura, sabor doce e adstringente muito particular e se destacam pela sua rica composição. As antocianinas presentes naturalmente no jamelão têm despertado interesse, devido aos seus efeitos nutricionais e terapêuticos, pela ação antioxidante (LAGO; GOMES; SILVA, 2006). Em comparação com outras frutas, o extrato dos frutos de Jamelão mostrou alta atividade antioxidante devido à presença de compostos bioativos como carotenóides e compostos fenólicos (FARIA; MARQUES; MERCADANTE, 2011).

No Brasil, o uso do amido de mandioca tem sido amplamente estudado para a produção de bioembalagens, uma vez que a mandioca é cultivada em todos os estados brasileiros, situando-se entre os nove primeiros produtos agrícolas do país, em termos de área cultivada, e o sexto em valor de produção (EMBRAPA, 2011).

Visando o aproveitamento da capacidade antioxidante dos compostos antociânicos do jamelão o presente trabalho objetiva a elaboração de filmes comestíveis, compostos por amido de mandioca como matriz principal com a adição de antioxidantes presentes nos frutos do Jamelão. Além de ser uma opção como conservante de alimentos o biofilme irá aproveitar de maneira sustentável o jamelão e a mandioca, recursos amplamente difundidos e com pouco uso tecnológico na nossa região.

\section{METODOLOGIA}

Os filmes comestíveis a base de amido de mandioca foram elaborados de acordo com a metodologia casting proposta por Shimazu, Mali e Grossmann (2007). Os materiais utilizados para a elaboração do biofilme serão amido de mandioca como matriz principal, água, de glicerol como plastificante e extrato dos frutos do jamelão como aditivo com propriedade antioxidante.

O extrato de Jamelão foi obtido por extração aquosa, com água destilada na proporção de 1:3 fruta : água, de acordo com a metodologia proposta por Roesler et al. (2007) com adaptações. $\mathrm{O}$ extrato bruto e o filme foram caracterizados fisico-quimicamente, com análise do teor de compostos fenólicos por meio da metodologia proposta por Roesler et al. (2007) com adaptações, através do método Folin Ciocalteau. A quantificação de 
fenóis é feita através de uma curva padrão de ácido gálico e o resultado expresso em equivalente de ácido gálico - GAE (mg GAE/g de amostra). As propriedades mecânicas de perfuração do filme foram determinadas de acordo com a metodologia proposta por Gontard, Guilbert, Cuq (1991).

Para o delineamento experimental, foram analisados os efeitos dos seguintes parâmetros: concentração de plastificante $\left(\mathrm{X}_{1}\right)$ e a concentração de extrato de jamelão $\left(\mathrm{X}_{2}\right)$, sobre a ação antioxidante do extrato e as propriedades mecânicas do filme. Os valores das variáveis independentes foram calculados segundo um planejamento fatorial $2^{2}$ com 8 ensaios fatoriais, com 3 repetições no ponto central.

\section{RESULTADOS E DISCUSSÃO}

Para desenvolvimento dos biofilmes no planejamento fatorial, os limites da concentração de plastificante e extrato foram definidos através de testes, que delimitaram as quantidades máximas e mínimas de ambas variáveis para a obtenção de um filme com propriedades satisfatórias. Os valores reais e codificados das variáveis independentes são mostrados na tabela 01 .

Tabela 01 - Variáveis e níveis do planejamento experimental $2^{2}$

\begin{tabular}{llllll}
\hline Variáveis & $\mathbf{- 1 , 4}$ & $\mathbf{- 1}$ & $\mathbf{0}$ & $\mathbf{+ 1}$ & $\mathbf{1 , 4}$ \\
\hline GLI (\%) & 8 & 10 & 15 & 20 & 22 \\
EXT (\%) & 16 & 20 & 30 & 40 & 44 \\
\hline
\end{tabular}

Os biofilmes elaborados com amido de mandioca e concentrações diversas de glicerol e extrato de Jamelão se apresentaram, em geral, manuseáveis, uniformes e transparentes. Os filmes com menores concentrações de plastificante tiveram maior rigidez e alguns se apresentaram quebradiços. Com relação ao extrato de Jamelão, quanto maior sua concentração melhor a elasticidade do filme, uma vez que os açúcares presentes no extrato da fruta atuaram como um plastificante extra.

$\mathrm{O}$ extrato aquoso de Jamelão apresentou uma alta concentração de compostos fenólicos, com um teor de 585,48 mgGAE/100g . A composição química depende da espécie, condições ambientais, e também sobre o estágio de maturação do fruto (VEBER, 2015). Nos biofilmes, os teores de fenóis das 11 formulações são mostrados na tabela 02 .

Tabela 02 - Respostas das variáveis dependentes de acordo com o planejamento fatorial $2^{2}$ do filme incorporado de extrato concentrado de jamelão.

\begin{tabular}{cccc}
\hline \multicolumn{3}{c}{ Variáveis dependentes } & Variável independente \\
\hline Ensaio & Glicerol $(\%)$ & Extrato $(\%)$ & Fenóis $(\mathbf{m g} / \mathbf{1 0 0 g})$ \\
\hline 1 & 10 & 20 & $201,63 \pm 0,002$ \\
2 & 10 & 40 & $269,05 \pm 0,011$ \\
3 & 20 & 20 & $208,11 \pm 0,022$ \\
4 & 20 & 40 & $265,28 \pm 0,020$ \\
5 & 7,95 & 30 & $219,43 \pm 0,011$ \\
6 & 22,05 & 30 & $230,76 \pm 0,017$ \\
7 & 15 & 15,9 & $197,32 \pm 0,004$ \\
8 & 15 & 44,01 & $299,79 \pm 0,007$
\end{tabular}




\begin{tabular}{rlll}
9 & 15 & 30 & $214,04 \pm 0,005$ \\
10 & 15 & 30 & $222,13 \pm 0,006$ \\
11 & 15 & 30 & $221,59 \pm 0,005$ \\
\hline
\end{tabular}

Como pode-se observar, os teores de fenóis nos biofilmes aumentaram proporcionalmente com a concentração de extrato de Jamelão na amostra. $\mathrm{O}$ filme 8 formulado com 44,1\% de extrato apresentou um teor de $299,79 \mathrm{mg} / 100 \mathrm{~g}$, sendo este o maior teor de compostos fenólicos encontrado. Na análise estatística da resposta Força (N) do filme de amido incorporado com extrato de jamelão foi verificado que houve efeito significativo do plastificante glicerol e do extrato de jamelão no mesmo.

No teste de perfuração a força de ruptura dos filmes variou de 2,55 a 3,61 N, com menor valor na formulação com $44 \%$ de extrato de Jamelão e $15 \%$ Glicerol. Com relação à deformação à perfuração, verifica-se que o menor valor $(12,85 \%)$ se encontra na faixa de combinações de glicerol $15 \%$ e extrato de jamelão $30 \%$.

Conforme Mali et. al (2005), o teor de plastificante empregado nos filmes de amido é um parâmetro largamente discutido, uma vez que o efeito que estes causam nas propriedades funcionais dos filmes depende não só da sua concentração, mas também do tipo de plastificante empregado. As variáveis independentes extrato e glicerol apresentaram efeito significativo sob as variáveis dependentes, apresentando uma redução na força de ruptura e deformação à ruptura com o aumento da concentração destes. O mesmo comportamento foi verificado por Vicentini (2003), com elaboração de filmes comestíveis à base de fécula de mandioca com adição de glicerol, sorbitol e dietilenoglicol como plastificantes.

Com relação ao teor de fenóis sua concentração aumentou linearmente com teor de extrato adicionado. Esta variável influenciou também as propriedades mecânicas dos filmes, com redução da força na ruptura e deformação, mesmo comportamento verificado por Farias et. al (2012), que elaboraram filmes com amido de mandioca adicionados de polpa de acerola, e que apresentou redução na força de $13,3 \mathrm{~N}$ para 3,7 N.

\section{CONSIDERAÇÕES FINAIS}

A elaboração de embalagens bioativas com adição de antioxidantes naturais é de grande interesse para a indústria de alimentos. A adição de glicerol conferiu maior manuseabilidade e menor força de ruptura na perfuração do filme, e o aumento da concentração extrato de Jamelão um maior teor de compostos fenólicos. O biofilme de amido de mandioca com adição de extrato de Jamelão apresenta-se como uma alternativa promissora no mercado, por realizar o aproveitamento de matérias-primas regionais na elaboração de uma embalagem bioativa com propriedade antioxidante, que pode ser utilizada na conservação de alimentos suscetíveis à oxidação, aumentando a vida de prateleira e evitando perdas na cadeia produtiva. Além de ser comestível e não agredir o meio ambiente.

\section{REFERÊNCIAS}

EMBRAPA. Empresa Brasileira de Pesquisa Agropecuária. Cultura da Mandioca. Brasilia, 2011. 
FARIA, A.F.; MARQUES, M.C.; MERCADANTE, A.Z. Identification of bioactive compounds from jambolão (Syzygium cumini) and antioxidant capacity evaluation in different pH conditions. Food Chemistry 126 (2011) 1571-1578.

FARIAS, M.G.; FAKHOURI, F.M.; CARVALHO, C.W.P.; ASCHERI, J.L.; Caracterização físico-química de filmes comestíveis de amido adicionado de acerola (Malphigia emarginata D.C.). Quim. Nova, Vol. 35, No. 3, 546-552, 2012.

GONTARD, N.; GUILBERT, S.; CUQ, J. L. Water and glycerol as plasticizers affect mechanical and water vapor barrier properties of an edible wheat gluten film. Journal of Food Science, v.58, n.1, p.206-211, 1991.

GUILBERT, S; BIQUET, B. Películas y envolturas comestibles. In: BUREAU, G.; MULTON, J.L. Embalaje de los alimentos de gran consume. Zaragosa: Acríbia, 1995. Cap 22, 331-371

MALI, S., GROSSMANN, M. V. E., GARCÍA, M. A., MARTINO, M. M.; ZARITZKY, N. E. Mechanical and thermal properties of yam starch films. Food Hydrocolloids , Oxford, v. 19, n. 1, p. 157- 164, 2005.

LAGO, E. S.; GOMES, E.; SILVA, R. Produção de geléia de jambolão (syzygium cumini lamarck): processamento, parâmetros físico - químicos e avaliação sensorial. Disponível em: $<$ http://www.scielo.br/pdf/\%0D/cta/v26n4/20.pdf $>$ Acesso em: março 2016.

ROESLER,R.; MALTA, L.G.;CARRASCO, L.C.; HOLANDA,R.B.; SOUSA,C.A.S.; PASTORE, G.M. Atividade antioxidante de frutas do cerrado. Ciênc. Tecnol. Aliment., Campinas, 27(1): 53-60, jan.-mar. 2007. Disponível em: <http://www.scielo.br/pdf/\%0D/cta/v27n1/09.pdf> Acesso em: março 2016.

SHIMAZU, A. A.; MALI, S.; GROSSMANN, M. V. E. Efeitos plastificante e antiplastificante do glicerol e do sorbitol em filmes biodegradáveis de amido de mandioca. Semina: Ciências Agrárias, Londrina, v. 28, n. 1, p. 79-88, jan./mar. 2007 VEBER, J. Determination of phenolic compounds and antioxidant capacity of aqueous and ethanolic extracts of Jambul (Syzygium cumini). Rev. bras. Plantas med. vol.17 no.2 Botucatu Apr./June 2015. 